\title{
To study the role of hysteroscopy and laparoscopy in the evaluation of infertility
}

\author{
Kimaya Mali ${ }^{1}$, Swadhin Mohanty ${ }^{2}$ \\ ${ }^{1}$ Department of Obstetrics and Gynaecology, Seth G.S. Medical College and KEM Hospital, Mumbai, Maharashtra, \\ India \\ ${ }^{2}$ Dr. Babasaheb Ambedkar Central Railway Hospital, Byculla (East), Mumbai, Maharashtra, India
}

Received: 03 July 2016

Accepted: 05 August 2016

*Correspondence:

Dr. Kimaya Mali,

E-mail: drkimaya123@gmail.com

Copyright: () the author(s), publisher and licensee Medip Academy. This is an open-access article distributed under the terms of the Creative Commons Attribution Non-Commercial License, which permits unrestricted non-commercial use, distribution, and reproduction in any medium, provided the original work is properly cited.

\begin{abstract}
Background: Infertility is defined as a lack of conception after at least 12 months of unprotected intercourse. Hysteroscopy and laparoscopy are the two methods widely used in assessing tubal patency, endometriosis, for diagnosis and treatment of polycystic ovaries, tub ovarian mass, peritubal adhesions. This study strives to undertake an in depth analysis of infertility with the help of hysteroscopy and laparoscopy to give a lucid picture to establish a diagnosis and subsequent treatment for the same.

Methods: This is a prospective study carried out in department of obstetrics and gynaecology at Dr. Babasaheb Ambedkar Central Railway Hospital, Mumbai in the year 2008. Women within the age of 20 to 40 with infertility were included in the study.

Results: There were 50 patients in the study out of which 35 cases were of primary infertility and 15 cases of secondary infertility. Most common age group was between 26 to 30 years in $42 \%$ cases. Hysteroscopy could detect abnormality in 12 cases $(24 \%)$ and the most common finding being fibroid. Laparoscopy could detect pathology in $74 \%$ of cases and the commonest pathology being PCOS $(28 \%)$.

Conclusions: Hysterolaparoscopy is a very good diagnostic tool for identification of certain problems like endometriosis, adhesions near adnexa etc. which are difficult to diagnose by other imaging modalities and even it can be used as the operative tool in certain situations while undergoing diagnostic test.
\end{abstract}

Keywords: Infertility, Hysteroscopy, Laparoscopy

\section{INTRODUCTION}

At a time when overpopulation is proving to be a crisis all over the world, especially in the developing countries, the age old dilemma of the sterile couple still remains to be completely solved. Infertility is a global conundrum. Approximately $10-15 \%$ couples fail to conceive. The definition of infertility varies among clinicians. In 1975, the WHO recommended more than 24 months of unprotected intercourse as the favoured definition. Later WHO changed the definition to "a lack of conception after at least 12 months of unprotected intercourse" (Rowe et al 1993). It is said that the gynaecologists must have eyes at the end of the fingers so that they can delineate the size, shape and position of the uterus and evaluate the adnexae. For this vaginal and bimanual examination is a must. Frequently gynaecologists encounter difficulty in making a diagnosis. But with the advent of sophisticated and newer modalities in diagnosing the cause of infertility, the patients are subjected to lesser trauma and the strain of going through exhaustive investigations. Hysteroscopy and laparoscopy are the two methods widely used in assessing tubal patency, endometriosis, for diagnosis and treatment of polycystic ovaries, tubo ovarian mass, peritubal adhesions. This study strives to undertake an in depth 
analysis of infertility with the help of hysteroscopy and laparoscopy to give a lucid picture to establish a diagnosis and subsequent treatment for the same.

\section{METHODS}

This retro prospective study was conducted at tertiary care centre at Dr. Babasaheb Ambedkar memorial central railway hospital from January 2008 to December 2008. Patients between the age group of 20 to 40 years were included in the study. The patients with primary as well as secondary infertility was included. Diagnostic Hysterolaparoscopy along with chromopertubation was carried out in infertile patients in early follicular phase from day 5 to day 8 . The instruments for Hysterolaparoscopy were of KARL STORZ, Germany.

\section{RESULTS}

Out of 50 cases 35 cases were of primary infertility and 15 cases were of secondary infertility. Women who presented with primary infertility were of age groups between 26 to 30 years while that of secondary infertility were between 30 to 35 years. Our study showed that women having various menstrual irregularities were associated with infertility. The most common menstrual abnormality was oligomenorrhea seem in 13 cases, followed by dysmenorrhea (7) and menorrhagia (4) (Table 1).

Table 1: Table of menstrual irregularities.

\begin{tabular}{|lll|}
\hline & No. of cases & Percentage \\
\hline Regular, (normal) & 23 & $46 \%$ \\
\hline Menorrhagia & 4 & $8 \%$ \\
\hline Dysmenorrhea & 7 & $14 \%$ \\
\hline Oligomenorrhea & 13 & $26 \%$ \\
\hline Hypomenorrhea & 3 & $6 \%$ \\
\hline
\end{tabular}

Study showed that most common hysteroscopic findings were abnormality of the uterine cavity due to fibroid along with septate uterus and polyps being the second common finding (Table 2).

Table 2: Hysteroscopic findings.

\begin{tabular}{|lll|}
\hline $\begin{array}{l}\text { Hysteroscopic findings } \\
\text { Uterine cavity } \\
\text { abnormal (fibroid) }\end{array}$ & No. of cases & Percentage \\
\hline Septum & 2 & $8 \%$ \\
\hline Atrophic endometrium & 1 & $4 \%$ \\
\hline Profuse endometrium & 2 & $2 \%$ \\
\hline Intrauterine adhesion & 1 & $4 \%$ \\
\hline Polyp & 2 & $2 \%$ \\
\hline
\end{tabular}

Out of the 50 patients who underwent Laparoscopy with chromopertubation, 13 cases $(26 \%)$ had no demonstrable pathology on laparoscopy and demonstrable pathology was found on in 37 cases (74\%). The abnormal laparoscopic findings are enumerated in Table 4 and Figure 1 and total $74 \%$ of abnormalities were found during laparoscopy amongst them the most common finding was PCOS comprising seen in 14 cases (74\%).

Table 3: Case distribution according to laparoscopic findings.

\begin{tabular}{|lll|}
\hline Laparoscopic findings & No. of cases & Percentage \\
\hline $\begin{array}{l}\text { No demonstrable } \\
\text { pathology }\end{array}$ & 13 & $26 \%$ \\
\hline $\begin{array}{l}\text { Demonstrable } \\
\text { pathology }\end{array}$ & 37 & $74 \%$ \\
\hline
\end{tabular}

Table 4: Distribution of abnormal laparoscopic findings.

\begin{tabular}{|lll|}
\hline Laparoscopic findings & No. of cases & Percentage \\
\hline Fibroid & 5 & $10 \%$ \\
\hline Endometriosis & 6 & $12 \%$ \\
\hline PCOS & 14 & $28 \%$ \\
\hline Genital kochs & 3 & $6 \%$ \\
\hline Dermoid & 1 & $2 \%$ \\
\hline PID & 8 & $16 \%$ \\
\hline Total & 37 & $74 \%$ \\
\hline
\end{tabular}

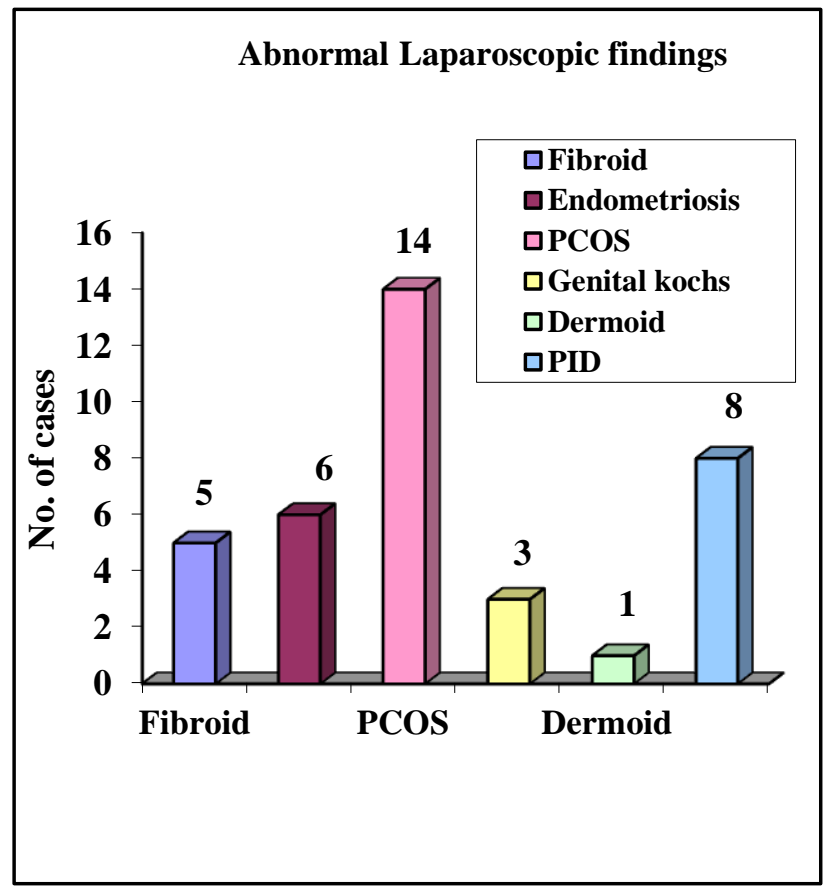

Figure 1: Bar diagram of abnormalities detected on laparoscopy.

Table 5: Table of tubal and peritoneal (32\%) pathology diagnosed by laparoscopy.

\begin{tabular}{|lll|}
\hline Pathology & No. of cases & Percentage \\
\hline Endometriosis & 6 & $12 \%$ \\
\hline Tuberculosis & 3 & $6 \%$ \\
\hline PID & 7 & $14 \%$ \\
\hline
\end{tabular}


The most common etiological factors in our study was found to be tubal and peritoneal factor (32\%) followed by ovarian factor $(30 \%)$ and uterine factor $(16 \%)$. Unexplained infertility was seen in 8 cases $(16 \%)$.

Table 6: Percentage of etiological factors in infertility.

\begin{tabular}{|lll|}
\hline Etiological factors & No. of cases & Percentage \\
\hline Uterine & 8 & $16 \%$ \\
\hline Ovarian & 15 & $30 \%$ \\
\hline Tubal and peritoneal & 16 & $32 \%$ \\
\hline Unexplained & 8 & $16 \%$ \\
\hline
\end{tabular}

Other than mild pain there was no major surgical or anesthetic complication seen in our study. Infertility is not a disease of an individual, rather it is the problem of a couple.

\section{DISCUSSION}

Factors from either one or both partners may contribute to difficulties in conceiving; therefore it is important to consider all possible causes in an infertile couple. In some cases, no specific causes are detected despite an extensive and complete evaluation. On the other hand, often more than one cause is identified in a couple. Therefore in the present study, all the couples, after thorough history and physical examination, were subjected to multiple directions of investigation culminating in hystero-laparoscopy. In our study, majority of the patients belonged to the age group of 2630 years and $2 \%$ of patients were between age group of 36-40 years. Majority of the patients presented with primary infertility of less than or equal to 5 years of duration as the couples are very anxious to conceive after marriage. ${ }^{1,2}$ The patients in our study, $54 \%$ had menstrual complaints whereas $46 \%$ had normal menses. Out of 27 patients $(54 \%), 13$ patients $(26 \%)$ had oligomenorrhea and 7 patients $(14 \%)$ had dysmenorrhea, 4 patients $(8 \%)$ had menorrhagia and 3 patients $(6 \%)$ had hypomenorrhea. So in our study population, amongst all menstrual abnormalities, oligomenorrhea and dysmenorrhea were the most common complaints. Out of these, majority of the patients with oligomenorrhea were further diagnosed to have PCOS which keeps in tandem with a study by Hull in 1986, who concluded that overt and occult PCOD accounted for $90 \%$ of the patients with oligomenorrhea and $37 \%$ with amenorrhea, $73 \%$ with oligo and amenorrhea. ${ }^{3}$ Oligo and amenorrhea accounted for $21 \%$ couples with infertility.

In our study patients having dysmenorrhea when further investigated were found to have endometriosis which keeps in trace with the study by Mahmood TA, Templeton AA et al who reported that dysmenorrhea is the most common reported symptom and severe form is highly suggestive of endometriosis. ${ }^{4}$ In our study group of 50 patients hysteroscopy detected abnormalities in 12 patients $(24 \%)$ and the remaining 38 patients $(76 \%)$ had no demonstrable pathologies uterine cavity was irregular due to fibroid in 4 patients (8\%), septum was detected in 2 patients $(4 \%)$ and polyps were detected in 2 patients $(4 \%)$.

Septum causes deficient implantations, both the patients which were detected to have uterine septum on hysteroscopy came with history of abortion in previous pregnancies. Hysteroscopic septum resection was done in both of them under laparoscopic guidance. Laparoscopic guided hysteroscopic metroplasty is safe and allows spontaneous delivery and short term pregnancy planning, in infertile women with history of more than 1 spontaneous abortions. ${ }^{5,6}$ Hysteroscopic polypectomy was done in 2 patients in our study. The exact site and location was identified and polyp was removed easily under hysteroscopic guidance with complete stalk removal.

One patient underwent hysteroscopic myomectomy, the fibroid was intra-cavitatory and hence complete excision was possible with hysteroscopic guidance. After myomectomy even the menstrual complaints of this patient decreased. ${ }^{9}$ Both these procedures enhanced the fertility of the patients thus showing that operative hysteroscopy helps in treatment of infertility and due to menorrhagia control following myomectomy, hysteroscopy also has therapeutic value. ${ }^{8}$

In the study by Nicole N, Varasteh, et al, concluded that hysteroscopic polypectomy and myomectomy appeared to enhance fertility as compared with women with normal uterine cavities. ${ }^{7}$ Persistent functional endometrial polyp, even if small are likely to impair fertility and removal of such lesions may improve subsequent reproductive performance. In my study of 50 patients with infertility, laparoscopy demonstrated pathologies in 37 patients (74\%) and 13 patients (26\%) had no pathologies. Among the patients with demonstrable pathology, polycystic ovarian disease was diagnosed in 14 patients (28\%) which was the most common finding in laparoscopy, endometriosis in 6 pts. (12\%), fibroid in 5 pts. (10\%), genital Koch's in 3 patients $(6 \%)$, dermoid cyst of the ovary was diagnosed in 1 patient $(2 \%)$ and pelvic inflammatory disease diagnosed in 8 patients $(16 \%)$. The cause of infertility in these patients could be due to anovulation (PCOS), mechanical obstruction, distorted anatomy, destruction of the fallopian tube, affecting fertilization and ovum pick up. Diagnostic laparoscopy should be performed on all women to search for a tubal or pelvic cause of infertility. ${ }^{10}$ And also in cases of unexplained infertility or in sub fertile women as many abnormalities were found following laparoscopy. ${ }^{10,11}$ Thus from our study, due to laparoscopy, various causes of infertility could be found and further treated. The presence of endometriosis in infertile patients in various studies range from $5-70 \%$, in my study, presence of endometriosis was in 6 pts $(12 \%)$.

Endometriosis regardless of its severity rarely causes radiographic abnormalities on HSG and therefore can be 
diagnosed only by laparoscopy. ${ }^{12}$ Definitive diagnosis of endometriosis is made after visualization of endometriotic lesions during laparoscopy and by histological confirmation of laparoscopic impression. Ablation of endometriotic lesions plus adhesiolysis to improve fertility in minimal-mild endometriosis is effective compared to diagnostic laparoscopy alone. ${ }^{13}$ Thus laparoscopy is considered a gold standard for the diagnosis of endometriosis. ${ }^{14}$ The other most common cause of infertility seen in India is Tuberculosis, and the incidence is almost 3.2 to $6.2 \%$ of genital tuberculosis affecting the fertility. ${ }^{15}$

\section{Table 7: Incidence of endometriosis in infertile} patients.

\begin{tabular}{|ll|}
\hline Study & $\begin{array}{l}\text { Presence of endometrioses } \\
\text { infertile women }\end{array}$ \\
\hline Multicentric Italian study & $30 \%$ \\
\hline Mohmoud and Templeton & $20-50 \%$ \\
\hline Caroline Wellbery et all & $20 \%$ \\
\hline Robertz et al & $15-70 \%$ \\
\hline Present study & $12 \%$ \\
\hline
\end{tabular}

4 patients were diagnosed as unexplained infertility; with the basic infertility work up done before hysterolaparoscopy. On hysterolaparoscopy the findings of minimal-mild endometriosis was found in 1 patient, 1 patient with genital Koch's and 2 patients with PID (peritubal adhesion) were diagnosed and treated subsequently. This shows that basic infertility workup is inadequate in diagnosing causes of infertility and needs hystero-laparoscopy for complete infertility workup.

\section{CONCLUSION}

Diagnostic hysterolaparoscopy is a very safe and effective tool for the evaluation of infertility. It is a used for the diagnosis and detection of conditions like endometriosis, tubal adhesions, uterine septum etc. and these abnormalities can be corrected which are missed during routine infertility investigations. Hysterolaparoscopy if done with proper selection of cases and in experience hands can be considered as the most effective tool for evaluation of infertility.

\section{Funding: Central Govt. of Railways}

Conflict of interest: None declared

Ethical approval: The study was approved by the Institutional Ethics Committee

\section{REFERENCES}

1. Boivin J, Bunting L, Collins JA, Nygren KG. International estimates of infertility prevalence and treatment-seeking: potential need and demand for infertility medical care. Hum Reprod. 2007;22:150612.
2. WHO laboratory manual for the examination of human semen and sperm-cervical mucus interaction. $4^{\text {th }}$ ed. Cambridge: Cambridge University Press. World Health Organization; 1999.

3. Miller JH, Weinberg RK, Canino NL, Klein NA, Soules MR. The pattern of infertility diagnoses in women of advanced reproductive age. Am J Obstet Gynecol. 1999;181:952-7.

4. Mol BW, Collins JA, Burrows EA, van der Veen F, Bossuyt PM. Comparison of hysterosalpingography and laparoscopy in predicting fertility outcome. Hum Reprod. 1999;14:1237-42.

5. Jayakrishnan K, Koshy AK, Raju R. Role of laparohysteroscopy in women with normal pelvic imaging and failed ovulation stimulation with intrauterine insemination. J Hum Reprod Sci. 2010;3:20-4.

6. Godinjak Z, Idrizbegovic E. Should diagnostic hysteroscopy is a routine procedure during diagnostic laparoscopy in infertile women. Bosn J Basic Med Sci. 2008;8:44-7.

7. Tsuji I, Ami K, Miyazaki A, Hujinami N, Hoshiai H. Benefit of diagnostic laparoscopy for patients with unexplained infertility and normal hysterosalpingography findings. Tohoku J Exp Med. 2009;219:39-42.

8. Wallach EE. The uterine factor in infertility. Fertil Steril. 1972;23:138-58.

9. Brown SE, Coddington CC, Schnorr J, Toner JP, Gibbons W, Oehninger S. Evaluation of outpatient hysteroscopy, saline infusion hysterosonography, and hysterosalpingography in infertile women: A prospective, randomized study. Fertil Steril. 2000;74:1029-34.

10. Romano F, Cicinelli E, Anastasio PS, Epifani S, Fanelli F, Galantino P. Sonohysterography versus hysteroscopy for diagnosing endouterine abnormalities in fertile women. Int $\mathbf{J}$ Gynaecol Obstet. 1994;45:253-60.

11. Mooney SB, Milki AA. Effect of hysteroscopy performed in the cycle preceding controlled ovarian hyperstimulation on the outcome of in vitro fertilisation. Fertil Steril. 2003;79:637-8.

12. Homer HA, Li TC, Cooke ID. The septate uterus: a review of management and reproductive outcome. Fertil Steril. 2000;73:1-14.

13. Grimbizis GF, Camus M, Tarlatzis BC, Bontis JN, Devroey P. Clinical implications of uterine malformations and hysteroscopic treatment results. Hum Reprod Update. 2001;7:161-74.

14. Kamiński P, Wieczorek K, Marianowski L. Usefulness of hysteroscopy in diagnosing sterility. Ginekol Pol. 1992;63:634-7.

15. Donnez J, Jadoul P. What are the implications of myomas on fertility? A need for a debate? Hum Reprod. 2002; 17:1424-30.

16. Pritts EA. Fibroids and infertility: a systematic review of the evidence. Obstet Gynecol Surv. 2001;56:483-91. 
17. Vollenhoven BJ, Lawrence AS, Healy DL. Uterine fibroids: a clinical review. Br J Obstet Gynaecol. 1990;97:285-98.

18. Hinckley MD, Milki AA. 1000 office-based hysteroscopies prior to in vitro fertilization: Feasibility and findings. JSLS. 2004;8:103-7.

19. Shalev J, Meizner I, Bar-Hava I, Dicker D, Mashiach R, Ben-Rafael Z. Predictive value of trans-vaginal sonography performed before routine diagnostic hysteroscopy for evaluation of infertility. Fertil Steril. 2000;73:412-7.

20. Shokeir TA, Shalan HM, EI-Shafei MM. Significance of endometrial polyps detected hysteroscopically in eumenorrheic infertile women. J Obstet Gynaecol Res. 2004;30:84-9.

Cite this article as: Mali K, Mohanty S. To study the role of hysteroscopy and laparoscopy in the evaluation of infertility. Int J Reprod Contracept Obstet Gynecol 2016;5:3027-31. 